\title{
Effect of dexmedetomidine pretreatment on a rat model of myocardial ischemia-reperfusion injury
}

\author{
Jingxia Chen ${ }^{1}$, Wenyan Liu ${ }^{1}$, Shuzhen Wang ${ }^{2}$, Zidong Zhang ${ }^{1}$, Weiguo Li $^{1 *}$ \\ ${ }^{1}$ Department of Anesthesiology, ${ }^{2}$ Department of Operating Room, The Eighth People's Hospital of Hengshui City, Hengshui \\ 253800, Hebei Province, China \\ *For correspondence: Email: ddzt38@163.com
}

Sent for review: 12 February 2021

Revised accepted: 26 May 2021

\begin{abstract}
Purpose: To study the effect of dexmedetomidine pretreatment on a rat model of myocardial ischemiareperfusion injury (IRI)

Methods: Three groups of $S D$ rats $(n=48$; mean body weight $=275 \pm 25 \mathrm{~g}$ ) were used (16 rats each): sham, IRI, and dexmedetomidine groups. Ischemia-reperfusion injury (IRI) was established via ligation of left anterior coronary artery. Rats in dexmedetomidine group were treated with single i.p. injection of dexmedetomidine $(100 \mu \mathrm{g} / \mathrm{kg}) 30 \mathrm{~min}$ before induction of IRI. Serum levels of IL-1 $\beta$, IL-6 and TNF- $\alpha$ were determined by enzyme-linked immunosorbent assay (ELISA). Western blotting was used to determine the protein expressions of bcl-2 and bax, while histopathological changes in rat myocardial tissue were determined with H\&E staining.

Results: Serum TNF- $\alpha, I L-1 \beta$ and IL-6 levels were significantly up-regulated in IRI rats, relative to sham rats, but were decreased by dexmedetomidine $(p<0.05)$. Dexmedetomidine significantly reduced the level of malondialdehyde (MDA) in myocardial tissues of IRI rats, but it increased superoxide dismutase $(S O D)$ activity $(p<0.05)$. It also markedly increased bcl-2 protein level, while the protein expression of bax was decreased $(p<0.05)$. Results of $H \& E$ staining showed that dexmedetomidine significantly mitigated IRI-induced damage.

Conclusion: Dexmedetomidine mitigates myocardial IRI in rats through suppression of inflammatory and apoptotic changes, and enhancement of physiological antioxidant potential. This finding may be useful for the management of myocardial ischemia-reperfusion injury.
\end{abstract}

Keywords: Apoptosis, Dexmedetomidine, Inflammatory cytokines, Myocardial ischemia-reperfusion injury, Oxidative stress

\begin{abstract}
This is an Open Access article that uses a fund-ing model which does not charge readers or their institutions for access and distributed under the terms of the Creative Commons Attribution License (http://creativecommons.org/licenses/by/4.0) and the Budapest Open Access Initiative (http://www.budapestopenaccessinitiative.org/read), which permit unrestricted use, distribution, and reproduction in any medium, provided the original work is properly credited.

Tropical Journal of Pharmaceutical Research is indexed by Science Citation Index (SciSearch), Scopus, International Pharmaceutical Abstract, Chemical Abstracts, Embase, Index Copernicus, EBSCO, African Index Medicus, JournalSeek, Journal Citation Reports/Science Edition, Directory of Open Access Journals (DOAJ), African Journal Online, Bioline International, Open-J-Gate and Pharmacy Abstracts
\end{abstract}

\section{INTRODUCTION}

Organs and tissues differ in their ischemic tolerance. Prolonged and persistent ischemia causes severe necrosis in tissues [1-3]. Blood deprivation from organs influences the clinical prognosis of stroke, hemorrhagic shock, organ transplants and myocardial infarction. An important consideration in ischemia is the restoration of blood perfusion, and this has become the primary strategy for clinical treatment of ischemic diseases [4]. However, studies have shown that restoration of blood flow after hypoperfusion does not result in reduction 
or recovery from IRI. It leads to dysfunction in cell metabolism and/or exacerbation of tissue damage. Although restoration of blood flow to an ischemic organ is vital for mitigation of permanent tissue lesion, reperfusion may exacerbate tissue injury in excess of that due to ischemia alone. Ischemia-reperfusion injury (IRI), a common pathological event during anesthesia, refers to blood re-flow caused by ischemia of myocardial tissue/cells, which leads to myocardial tissue injury $[5,6]$. It has been reported that apoptosis, inflammation and oxidative stress may contribute to IRI [7]. Reperfusion of ischemic tissues leads to local and systemic inflammatory responses that may lead to aggravated microvascular dysfunction and altered tissue barrier function. Dexmedetomidine is a highly selective $\alpha 2$ receptor agonist which has shown great promise as an analgesic and a sedative. There are reports that dexmedetomidine effectively reduced the concentrations of circulating catecholamines, cardiac load and myocardial oxygen consumption. The drug has also been demonstrated to be effective against myocardial IRI [8]. Dexmedetomidine alleviated visual dysfunction caused by hypoxia-reoxygenation $(H / R)$ in rats via activation of a2-adrenergic receptors [9]. The present research was aimed at investigating the influence of dexmedetomidine pretreatment on myocardial IRI in rats.

\section{EXPERIMENTAL}

\section{Materials}

Dexmedetomidine was purchased from Shanghai Rongweida Industrial Co. Ltd. Hematoxylin was obtained from Chuzhou Shinuoda Biological Technology Co. Ltd. Eosin solution was product of Shanghai Jizhi Biochemical Technology Co. Ltd, while RIPA buffer was produced by Harbin Xinhai Gene Testing Co. Ltd; BCA kit was supplied by Guangzhou Weijia Tech. ELISA kit was bought from Nanjing Saihongrui Biological Technology Co. Ltd., while bax and bcl-2 antibodies were obtained from Shenzhen Haodi Huatuo Biotechnology Co. Ltd. Oven was purchased from Beijing Wokai Biotechnology Co. Ltd. Table centrifuge was bought from Beckman Coulter Trading Co. Ltd. (China). Light microscope was product of Olympus Sales and Service Co. Ltd. (Beijing). Sterile workbench was purchased from Hangzhou Nuoding Scientific Equipment Co. Ltd.

\section{Rats}

Specific pathogen-free Sprague Dawley rats used in this study $(n=48$; mean body weight $=$
$275 \pm 25 \mathrm{~g}$ ) were obtained from Wuxi Xinrun Biotechnology Co. Ltd. The rats were given feed and water ad libitum under equal light/dark photoperiod, and maintained at a temperature of $25 \pm 5{ }^{\circ} \mathrm{C}$ and $55 \%$ humidity. The rats were adapted to lab atmosphere for one week prior to starting the research which received approval from Ethical Committee of The Eighth People's Hospital of Hengshui City (approval no. 201980321), and was conducted according to "Principles of Laboratory Animal Care" (NIH publication no. 85-23, revised 1985) [10].

\section{Experimental design}

Three (3) groups of rats were used (16 animals/group): sham, IRI, and dexmedetomidine groups. Ischemia-reperfusion injury (IRI) was established via blockage of left anterior coronary artery. Rats in dexmedetomidine group were treated with single i.p. injection of dexmedetomidine $(100 \mu \mathrm{g} / \mathrm{kg}) 30 \mathrm{~min}$ before induction of IRI, while those in sham group received equivalent volume of normal saline intraperitoneally.

\section{Histopathological examination of rat myocardial tissue}

Excised myocardial tissue was fixed with $10 \%$ formaldehyde and then embedded with paraffin. Then, $5 \mu \mathrm{m}$ thick tissue sections were stained with H\&E and examined under light microscopy. Pathological changes in rat myocardial tissue were recorded and analyzed with ImageJ analysis software.

\section{Determination of protein expressions of apoptosis-related genes}

Protein expression levels of bcl-2 and bax in ischemic myocardial tissues of rats were measured with Western blotting. Rat myocardial tissue was homogenized in PBS and lysed with ice-cold RIPA buffer mixed with PMSF (1:10, v: v). The lysate protein content was measured with BCA method. Thereafter, $50-\mu \mathrm{g}$ protein portions were resolved with SDS-PAGE and electrotransferred to PVDF membrane. Then, the membrane was incubated with $5 \%$ fat-free milk solution (for sealing). Thereafter, membrane incubation was done for $12 \mathrm{~h}$ at $4{ }^{\circ} \mathrm{C}$ with the appropriate $1^{\circ}$ antibodies diluted 1: 1000, followed by incubation with HRP-linked $2^{\circ}$ antibody for $45 \mathrm{~min}$ at room temperature. Then, blot development was done with X-ray film, while ImageJ Launcher software was employed for band grayscale analysis. Extent of protein expression was normalized to $\beta$-actin which served as standard. 


\section{Measurement of levels of inflammatory cytokines}

Abdominal aortic blood ( $2 \mathrm{~mL}$ ) was drawn from each rat and centrifuged at $3500 \mathrm{rpm}$ to obtain serum, and the cytokines were assayed with their respective ELISA kits.

\section{Determination of antioxidant status in rat} myocardial tissue

Ischemic myocardial tissue of each rat was homogenized with ice-cold PBS and spun at $3500 \mathrm{rpm}$ for $10 \mathrm{~min}$ to obtain a clear supernatant. The level of MDA and activity of SOD in the supernatant were determined with thiobarbituric acid and xanthine oxidase reaction methods, respectively.

\section{Malondialdehyde assay}

Exactly $0.1 \mathrm{~mL}$ of $10 \%$ tissue homogenate was thoroughly mixed with $0.1 \mathrm{~mL}$ of anhydrous ethanol, $0.1 \mathrm{~mL}$ of reagent 1 , and $0.1 \mathrm{~mL}$ of 10 $\mathrm{nmol} / \mathrm{mL}$ standard solution. Then, $3 \mathrm{~mL}$ of reagent 2 and $1 \mathrm{~mL}$ of reagent 3 were serially added and incubated in a water bath at $95{ }^{\circ} \mathrm{C}$ for $45 \mathrm{~min}$. The mixture was centrifuged at $3500 \mathrm{rpm}$ for $10 \mathrm{~min}$ to obtain clear supernatant, the absorbance of which was read at $532 \mathrm{~nm}$.

\section{Superoxide dismutase (SOD) assay}

Tissue homogenate (1 \%) was diluted with distilled water, followed by serial additions of reagents $1,2,3$ and $4(1.0,0.1,0.1$ and $0.1 \mathrm{~mL}$, respectively. The resultant mixture was thoroughly mixed, followed by incubation in a 37${ }^{\circ} \mathrm{C}$ water bath for $42 \mathrm{~min}$. Then, $2 \mathrm{~mL}$ of colorimetric reagent was added and incubated for $20 \mathrm{~min}$ at room temperature, after which absorbance was read at $550 \mathrm{~nm}$.

\section{Statistical analysis}

Measurement data are expressed as mean \pm SEM. Statistical analysis was performed with SPSS (version 23.0). Groups were compared using SNK-q test and Student's $t$-test. Statistical significance was assumed at $p<0.05$.

\section{RESULTS}

\section{Influence of dexmedetomidine on histology of rat myocardial tissue}

The results of $\mathrm{H}$ \& $\mathrm{E}$ staining (Figure 1) showed that rats in the sham group exhibited normal architecture of myocardial tissue. The cells were neatly and compactly arranged, with large and round nuclei having visible nucleoli. In contrast, myocardial tissue cells of IRI rats were highly disorganized and vacuolated, with pyknotic nuclei. The cell structure was markedly distorted, and they appeared triangular, rectangular, spindle-shaped or irregular. However, dexmedetomidine significantly repaired the damage caused by IRI.

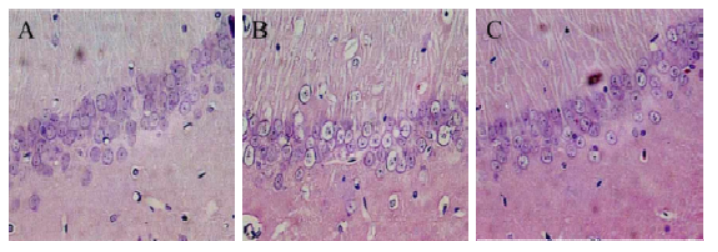

Figure 1: Comparison of pathological changes in rat myocardial tissue. (A): $\mathrm{H} \& \mathrm{E}$ staining of myocardial tissues of rats in sham group; (B): Results of H\&E staining of myocardial tissues of rats in IRI group; and (C): Results of histopathological examination of myocardial tissues of IRI rats pretreated with dexmedetomidine

\section{Effect of dexmedetomidine on protein expressions of apoptosis-related genes}

Pretreatment of IRI rats with dexmedetomidine markedly increased the protein expression of bcl2 , but it reduced bax protein expression (Figure 2).

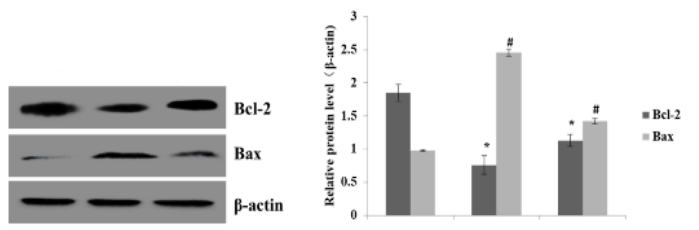

Figure 2: Effect of dexmedetomidine on protein expressions of apoptosis-related genes. (A): Protein levels of bcl-2 and bax; and (B): quantified Western blotting results. ${ }^{*} P<0.05$, vs sham; ${ }^{*} p<0.05$, vs IRI

\section{Effect of dexmedetomidine on levels of inflammatory cytokines in rat serum}

As shown in Table 1, the cytokine levels were markedly higher in IRI rat than in sham operation rats. However, dexmedetomidine significantly reduced the serum levels of these proinflammatory cytokines, when compared to the corresponding levels in IRI rats $(p<0.05)$.

\section{Effect of dexmedetomidine on antioxidant status of rat myocardial tissue}

The serum MDA level of IRI rats was markedly higher than that of the sham operation group, while SOD activity in IRI rats was markedly reduced, when compared to sham operation rats. 
However, dexmedetomidine significantly reduced the level of MDA in myocardial tissues of IRI rats, while it raised SOD activity $(p<0.05$; Table 2$)$.

Table 1: Serum levels of inflammatory cytokines in the rats (mean $\pm S D, n=16)$

\begin{tabular}{lccc}
\hline Group & $\begin{array}{c}\text { IL- } \\
\mathbf{1} \boldsymbol{\beta}(\mathbf{n g} / \mathbf{m L})\end{array}$ & $\begin{array}{c}\text { IL- } \\
\mathbf{6}(\mathbf{n g} / \mathbf{m L})\end{array}$ & $\begin{array}{c}\text { TNF- } \\
\boldsymbol{\alpha}(\mathbf{n g} / \mathbf{m L})\end{array}$ \\
\hline \multirow{4}{*}{ Sham } & $2.68 \pm 0.45$ & 0.32 & $1.09 \pm 0.24$ \\
& & $2.58 \pm$ & $1.97 \pm$ \\
IRI & $3.72 \pm 0.38^{*}$ & $0.38^{*}$ & $0.26^{*}$ \\
Dexmedeto & & $2.07 \pm$ & $1.64 \pm$ \\
midine & $3.03 \pm 0.34^{\#}$ & $0.30^{\#}$ & $0.22^{\#}$ \\
$F$ & 29.060 & 27.820 & 54.650 \\
$P$-value & $<0.001$ & $<0.001$ & $<0.001$ \\
\hline${ }^{*} P<0.05$, vs sham; ${ }^{\#} p<0.05$, vs IRI rats
\end{tabular}

Table 2: MDA level and SOD activity among the groups (mean $\pm S D, n=16$ )

\begin{tabular}{lcc}
\hline Group & MDA (nmol/mL) & SOD (U/mL) \\
\hline Sham & $1.92 \pm 0.49$ & $86.41 \pm 6.81$ \\
$I R I$ & $4.10 \pm 0.44^{*}$ & $43.52 \pm 2.41^{*}$ \\
Dexmedetomidine & $2.83 \pm 0.57^{\#}$ & $65.36 \pm 4.49^{\#}$ \\
$F$ & 75.860 & 305.170 \\
$P$-value & $<0.001$ & $<0.001$ \\
\hline${ }^{*} P<0.05$, vs sham; ${ }^{\#} p<0.05$, vs IRI rats
\end{tabular}

\section{DISCUSSION}

Reperfusion injury, sometimes called IRI or reoxygenation injury, is due to tissue lesion arising from post-ischemia restoration of blood flow. Research on the prevention and treatment of myocardial IRI has attracted huge attention in recent times. This has led to sustained effort at discovering novel factors that can effectively reduce the risk associated with the disease.

Dexmedetomidine is widely used as an anesthetic agent. It has been reported to effectively protect the heart, kidney, lung and other vital organs in animal models of IRI through regulation of inflammatory responses, and inhibition of caspase-3 and cell apoptosis [11]. Studies have shown that the use of dexmedetomidine in patients with cardiovascular diseases during surgery results in maintenance of hemodynamic stability, facilitation of intraoperative management, and reduction of risk associated with cardiac injury [12].

In this study, a rat IRI model was generated via ligation of the anterior branch of left coronary artery. The results obtained showed that dexmedetomidine significantly repaired pathomorphological damage in myocardial tissues of IRI rats. These results indicate that dexmedetomidine may significantly alleviate myocardial IRI in rats. Previous studies showed that reperfusion induced by ischemia or hypoxia caused cell necrosis and apoptosis, thereby making apoptosis a likely underlying mechanism [13].

It has been established that bax is a proapoptotic gene, while bcl-2 functions as an antiapoptotic gene. The homodimer, bcl-2-bcl-2 and heterodimer, bcl-2-bax, are produced when the expression level of bcl-2 is increased, so as to block cell apoptosis [14]. However, when the level of expression of bax is increased, bax-bax homodimer is produced, thereby resulting in a pro-apoptotic role [15]. In this study, pretreatment of IRI rats with dexmedetomidine markedly increased bcl-2 protein, and markedly reduced that of bax. These results suggest that dexmedetomidine may inhibit apoptosis of myocardial tissue cells of IRI rats.

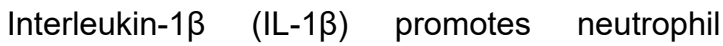
aggregation and adhesion; IL-6 regulates inflammatory response, while TNF- $\alpha$ facilitates the infiltration of inflammatory cells in ischemic areas. It has been reported that IL-1 $\beta$, IL- 6 and TNF- $\alpha$ are involved in acute myocardial infarction and IRI [16]. Inflammatory response is partially responsible for the damage caused by IRI. The results of this study showed that the IRI-induced increases in serum IL-1 $\beta$, IL- 6 and TNF- $\alpha$ were markedly decreased by dexmedetomidine. It is likely that dexmedetomidine may effectively block inflammatory response in IRI rats as a way of protecting the myocardial tissue from damage.

Oxidative stress has been speculated as a likely mechanism involved in myocardial IRI. Superoxide dismutase (SOD) and MDA are sensitive indicators of oxidative stress [17]. In patients with myocardial IRI, MDA level and glutathione peroxidase activity are markedly elevated, while SOD activity is significantly reduced by dexmedetomidine administration [18]. Dexmedetomidine markedly reduced the level of MDA in myocardial tissues of IRI rats, and markedly increased SOD activity, an indication that dexmedetomidine may significantly alleviate oxidative stress-induced myocardial injury in IRI rats.

\section{CONCLUSION}

Dexmedetomidine mitigates myocardial IRI in rats through suppression of inflammatory and apoptotic changes, and enhancement of physiological antioxidant potential. Thus, the compound can potentially be developed for management of myocardial IRI. 


\section{DECLARATIONS}

\section{Conflict of interest}

No conflict of interest is associated with this work.

\section{Contribution of authors}

We declare that this work was performed by the authors named in this article and all liabilities pertaining to claims relating to the content of this article will be borne by the authors. Weiguo $\mathrm{Li}$ designed the study, supervised the data collection, and analyzed the data. Jingxia Chen and Wenyan Liu interpreted the data and prepared the manuscript for publication. Shuzhen Wang, Zidong Zhang and Weiguo Li supervised the data collection, analyzed the data and reviewed a draft of the manuscript. Jingxia Chen and Wenyan Liu contributed equally to this work and should be considered as co-first authors.

\section{Open Access}

This is an Open Access article that uses a funding model which does not charge readers or their institutions for access and distributed under the terms of the Creative Commons Attribution License (http://creativecommons.org/licenses/by/ 4.0) and the Budapest Open Access Initiative (http://www.budapestopenaccessinitiative.org/rea d), which permit unrestricted use, distribution, and reproduction in any medium, provided the original work is properly credited.

\section{REFERENCES}

1. Jeong H, Yim HW, Park HJ, Cho Y, Hong H, Kim NJ, Oh IH. Mesenchymal Stem Cell Therapy for Ischemic Heart Disease: Systematic Review and Meta-analysis. Int $J$ Stem Cells 2018; 11(1): 1-12.

2. Liu B, Zhao G, Jin L, Shi J. Nicotinamide Improves Cognitive Function in Mice with Chronic Cerebral Hypoperfusion. Front Neurol 2021; 12: 1-10.

3. Li D, Lixia Y, Fengsui L, Haitao Z, Xinwei C. Farrerol ameliorates diabetic hepatopathy in rat model of type 2 diabetes mellitus via modulation of oxidativeinflammatory stress. Trop J Pharm Res 2020; 19 (1): 71 76.

4. Daly B, Toulis KA, Thomas N, Gokhale K, Martin J, Webber J, Keerthy $D$, Jolly $K$, Saravanan $P$, Nirantharakumar $K$. Increased risk of ischemic heart disease, hypertension, and type 2 diabetes in women with previous gestational diabetes mellitus, a target group in general practice for preventive interventions: $A$ population-based cohort study. PLoS Med 2018; 15(1): e1002488.
5. Cui HX, Chen JH, Li JW, Cheng FR, Yuan K. Protection of Anthocyanin from Myrica rubra against Cerebral Ischemia-Reperfusion Injury via Modulation of the TLR4/NF-KB and NLRP3 Pathways. Molecules 2018; 23(7): 1788.

6. Zhou H, Wang J, Zhu P, Zhu H, Toan S, Hu S, Ren J, Chen Y. NR4A1 aggravates the cardiac microvascular ischemia reperfusion injury through suppressing FUNDC1-mediated mitophagy and promoting Mffrequired mitochondrial fission by CK2a. Basic Res Cardiol 2018; 113(4): 1-20.

7. Sun $M S$, Jin $H$, Sun $X$, Huang $S$, Zhang $F L$, Guo ZN, Yang Y. Free Radical Damage in Ischemia-Reperfusion Injury: An Obstacle in Acute Ischemic Stroke after Revascularization Therapy. Oxid Med Cell Longev 2018; 2018: 3804979.

8. Li $H$, Zhang $X$, Chen $M$, Chen J, Gao $T$, Yao S. Dexmedetomidine inhibits inflammation in microglia cells under stimulation of LPS and ATP by CFos/NLRP3/caspase-1 cascades. Excli J 2018; 17: 302311.

9. Lv M, Zeng H, He Y, Zhang J, Tan G. Dexmedetomidine promotes liver regeneration in mice after $70 \%$ partial hepatectomy by suppressing NLRP3 inflammasome not TLR4/NFKB. Int Immunopharmacol 2018; 54: 46-51.

10. World Health Organization. Principles of laboratory animal care. WHO Chron 1985; 39: 51-56.

11. Rahimzadeh $P$, Faiz SHR, Imani $F$, Derakhshan $P$, Amniati S. Comparative addition of dexmedetomidine and fentanyl to intrathecal bupivacaine in orthopedic procedure in lower limbs. BMC Anesthesiol 2018; 18(1): 1-7.

12. Lee-Archer P, McBride C, Paterson R, Reade M, Reglivon Ungern-Sternberg $B$, Long $D$. Does dexmedetomidine given as a premedication or intraoperatively reduce post-hospitalisation behaviour change in children? A study protocol for a randomised controlled trial in a tertiary paediatric hospital. BMJ Open 2018; 8(4): 1-7.

13. Gochi T, Matsumoto K, Amin R, Kitazawa T, Seto K, Hasegawa T. Cost of illness of ischemic heart disease in Japan: a time trend and future projections. Environ Health Prev Med 2018; 23(1): 1-7.

14. Sun $Y$, Hu B, Wang Q, Ye M, Qiu Q, Zhou Y, Zeng F, Zhang $X$, Guo $Y$, Guo L. Long non-coding RNA HOTTIP promotes $B C L-2$ expression and induces chemoresistance in small cell lung cancer by sponging miR-216a. Cell Death Dis 2018; 9(2): 1-17.

15. Wei L, Chen Q, Guo A, Fan J, Wang R, Zhang H. Asiatic acid attenuates CCl4-induced liver fibrosis in rats by regulating the PISK/AKT/mTOR and Bcl-2/Bax signaling pathways. Int Immunopharmacol 2018; 60: 1-8.

16. Ma T, Liu X, Cen Z, Xin C, Guo M, Zou C, Song W, Xie $R$, Wang $K$, Zhou $H$, et al. MicroRNA-302b negatively regulates IL-1 $\beta$ production in response to MSU crystals by targeting IRAK4 and EphA2. Arthritis Res Ther 2018; 20(1): 1-11.

Trop J Pharm Res, June 2021; 20(6): 1183 
17. Wang W, Wen D, Duan W, Yin J, Cui C, Wang Y, Li Z, Liu Y, Li C. Systemic administration of ScAAV9-IGF1 extends survival in SOD1G93A ALS mice via inhibiting p38 MAPK and the JNK-mediated apoptosis pathway. Brain Res Bull 2018; 139: 203-210.
18. Mali AV, Joshi AA, Hegde MV, Kadam SS. Enterolactone modulates the ERK/NF-KB/Snail signaling pathway in triple-negative breast cancer cell line MDA-MB-231 to revert the TGF- $\beta$-induced epithelial-mesenchymal transition. Cancer Biol Med 2018; 15(2): 137-156. 